\title{
ARAHAN DAN MANAJEMEN PENGANGKUTAN SAMPAH DI KECAMATAN PONDOK GEDE KOTA BEKASI
}

\author{
Sodikin \\ Universitas Islam Negeri (UIN) Syarif Hidayatullah Jakarta \\ Email: shodiq_cahbageur@yahoo.com \\ Naskah diterima : 2 April 2015, direvisi : 16 April 2015, disetujui : 7 Mei 2015
}

\begin{abstract}
Garbage in Indonesia is still a difficult problem to solve, this occurs due to the amount of litter were increasingly grow in line with population growth. Sub Pondok Gede Bekasi City is located on the border with East Jakarta, has a large population growth is $3.48 \%$ / year this led to increasingly dense population density, which affects the volume of waste produced by the population every day. Based on the analysis, it is known that the volume of waste generated in the district population Pondok Gede in 2010 with a population of 235579 inhabitants is 188464 M3. After the projected population in 2025 will amount to be 358551 inhabitants and the volume of waste would be increased to 322696 M3. Direction and management of solid waste transportation is done by determining the number of polling stations and the number of trucks needed for all the rubbish served and can be transported. Based on the results of the analysis of the number of trucks required range of 2010 to 2005 ranged from 7 trucks to 11 trucks, TPS (temporary location) needed in 2010 was 524 units and in 2025 increased to 897 unit.
\end{abstract}

Keywords: tutorial; management; tansportation; garbage

\begin{abstract}
Abstrak
Artikel ini bertujuan untuk mengurai permasalahan sampah yang sulit dipecahkan akibat jumlah sampah yang kian hari kian bertambah seiring dengan meningkatnya jumlah penduduk di Kecamatan Pondok Gede Kota Bekasi. Metode yang digunakan adalah metode deskriptif. Data diperoleh melalui observasi dan analisis dari data sekunder. Data sekunder dalam penelitian ini antara lain data jumlah penduduk, peta administratif, data daerah pelayanan. Berdasarkan hasil analisis, diketahui volume sampah yang di hasilkan penduduk di Kecamatan Pondok Gede pada tahun 2010 dengan jumlah penduduk 235.579 jiwa adalah 188.464 M3. Setelah penduduk di proyeksikan pada tahun 2025 akan berjumlah menjadi 358.551 jiwa dan volume sampah akan mengalami peningkatan menjadi 322.696 M3. Arahan dan manajemen pengangkutan sampah dilakukan dengan penentuan jumlah TPS dan jumlah truk yang dibutuhkan agar semua sampah terlayani dan bisa terangkut. Berdasarkan hasil analisis jumlah truk yang dibutuhkan rentang tahun 2010 sampai 2005 berkisar mulai dari 7 truk sampai 11 truk, TPS (Tempat Penampungan Sementara) yang dibutuhkan pada tahun 2010 adalah 524 unit dan pada tahun 2025 meningkat menjadi 897unit.
\end{abstract}

Kata kunci: arahan; manajemen; pengangkutan sampah

Pengutipan: Sodikin. (2015). Arahan dan Manajemen Pengangkutan Sampah di Kecamatan Pondok Gede Kota Bekasi. SOSIO DIDAKTIKA: Social Science Education Journal, 2(1), 2015, 50-57. doi:10.15408/ sd.v2i1.1410

Permalink/DOI: http://dx.doi.org/10.15408/sd.v2i1.1410 


\section{A. Pendahuluan}

Persampahan di perkotaan di Indonesia saat ini masih menjadi masalah yang sulit untuk dipecahkan, salah satunya adalah peningkatan jumlah penduduk yang besar akan meningkatkan volume sampah yang dihasilkan dalam setiap harinya. Manajemen pengelolaan sampah mempunyai peranan yang sangat penting untuk mengatasi permasalahan sampah saat ini, apabila salah dalam melakukan pengelolaan, sampah akan menjadi menumpuk dan berdampak pada menurunnya kesehatan manusia, seperti munculnya berbagai macam penyakit yang bersumber dari pembusukan sampah.

Kecamatan Pondok Gede adalah salah satu kecamatan yang terdapat di Kota Bekasi. Kecamatan ini merupakan kecamatan terluas di Kota Bekasi. Pertumbuhan penduduk di kecamatan ini tergolong sangat tinggi yaitu 3,48\% sehingga pada tahun 2010 jumlah penduduk di Kecamatan Pondok Gede sebanyak 235.579 jiwa. Pertumbuhan penduduk yang cukup besar ini meningkatkan volume sampah yang dihasilkan setiap harinya sehingga sangat dibutuhkan manajemen sampah yang baik khususnya manajemen pengangkutan dari penghasil sampah agar terangkut dengan optimal. Oleh karena itu tujuan penulisan ilmiah ini adalah untuk memberikan arahan mengenai manajemen pengangkutan sampah di Kecamatan Pondok Gede Kota Bekasi.

\section{B. Tinjauan Pustaka}

\section{Pengertian Sampah}

Sampah merupakan hasil sisa dari kegiatan manusia karena sudah tidak memiliki manfaat lagi. Menurut Nugraha, "sampah adalah barang atau material sisa yang tidak diinginkan dari hasil akhir sebuah proses tertentu". ${ }^{1}$ Disamping itu terdapat UU yang menjelaskan tentang sampah beserta pengelolaannya. Menurut UU No. 18 Tahun 2008 "sampah adalah sisa kegiatan sehari-hari manusia dan/atau proses alam yang berbentuk padat". ${ }^{2}$

\footnotetext{
1 Adrian R. Nugraha, Menyelamatkan Lingkungan Hidup dengan Pengelolaan Sampah, (Jakarta: PT. Cahaya Pustaka Raga, 2010), hal.

2 Undang Undang No. 18 Tahun 2008 Tentang Pengelolaan Sampah
}

\section{Sumber dan Klasifikasi Sampah}

Menurut Yul Harry Bahar, sumber sampah berasal dari, domestic refuse, biasanya sampah yang berasal dari sisa makanan, bahan padat, yang sudah tidak terpakai lagi dalam rumah tangga, sisa pengolahan makanan, bahan pembungkus, bermacam-macam kertas, kain bekas, kaleng dan lain-lain. Sumber sampah berikutnya Comercial refuse adalah sampah yang berasal dari tempat-tempat perdagangan seperti pasar, supermarket, pusat pertokoan, warung dan tempat jual beli lainnya. Industrial refuse merupakan sampah yang berasal dari kegiatan industri, jumlah dan jenisnya sangat tergantung pada jenis dan jumlah bahan yang diolah oleh perusahaan industri tersebut. ${ }^{3}$

Secara umum sampah dapat digolongkan menjadi dua yaitu sampah yang mudah terurai dan yang tidak mudah atau tidak dapat terurai. Menurut Yul Harry Bahar, Degradable refuse yaitu sampah yang mudah terurai secara alami melalui proses fisik, kimiawi, maupun biologis. Biasanya sampah golongan ini berasal dari bahan-bahan organik, seperti sampah sayuran dan buahbuahan, sisa makanan, kertas, bangkai, binatang dan lain-lain. Nondegradable refuse adalah sampah yang tidak dapat diuraikan atau sulit diuraikan secara alami melalui proses fisik, kimiawi dan biologis menjadi molekul-molekul yang lebih kecil. Sampah ini biasanya berasal dari bahan anorganik, bahan sintetis dan bahan kertas lainnya, seperti metal, kaca, plastik, kayu dan keramik. ${ }^{4}$

Sampah basah atau organik yaitu sampah yang biasa dihasilkan dari rumah tangga, misalnya sisa sayuran, sisa makanan, daun-daunan, sisa buah-buahan atau sampah lainnya yang mudah membusuk. Biasanya sampah basah ini banyak juga dihasilkan dari pembuangan sampah yang berasal dari pasar-pasar yang menjual kebutuhan sehari-hari untuk masyarakat. Sampah basah ini biasa digunakan untuk pembuatan kompos. Sedangkan sampah kering atau yang biasa disebut sampah anorganik yaitu sampah yang tidak dapat membusuk seperti plastik, kertas, bahan sintetik, logam, kaleng, kaca dan lain-lain biasa di daur ulang untuk membuat produkproduk baru.

\footnotetext{
3 Bahar, Yul Harry. Teknologi Penangan dan Pemanfaatan Sampah, Jakarta: PT. Wacana Utama Pramesti, 1986.

$4 \quad$ Ibid,. Bahar, Yul Harry.
} 


\section{Pengelolaan Sampah}

Pengelolaan sampah meliputi pengumpulan, pengangkutan dan pembuangan. Selain itu penimbunan dan insinerasi (proses pembakaran sampah) menjadi cara menangani sampah.

a) Pengumpulan Sampah

Proses pengumpulan sampah harusnya dilakukan dengan cara memilah sampah berdasarkan jenisnya. Pengumpulan sampah yang tidak sesuai dengan tempatnya dapat menjadi salah satu masalah dari pencemaran lingkungan. Menurut Nugraha, pengumpulan sampah ialah pengumpulan sampah dari bak-bak sampah yang ada di rumah-rumah, kantor, pasar dan sebagainya. ${ }^{5}$ Pengumpulan sampah yang ditentukan pada suatu lokasi akan mempermudah proses pengelolaan sampah berikutnya.

\section{b) Pengangkutan}

Pengangkutan sampah sebaiknya dilakukan oleh tenaga ahli dibawah pengawasan dinas kebersihan. Pengangkutan dalam skala rumah tangga biasanya menggunakan gerobak untuk dikumpulkan di tempat pembuangan sementara. Dalam skala yang lebih besar maka menggunakan truk atau kontainer dalam proses pengangkutan ke tempat pembuangan akhir. Sebaiknya pengangkutan sampah menggunakan kendaraan tertutup guna meminimalisir pencemaran udara. Saat ini Indonesia masih menggunakan truk terbuka saat mengangkut sampah sehingga menimbulkan bau tidak sedap saat melewati jalan.

\section{c) Pembuangan}

Sampah yang telah terkumpul harus diangkut ke tempat pembuangan sampah. Masih menurut Nugraha, "maksud tempat buangan sampah adalah tempat pembuangan sampah terakhir setelah dikumpulkannnya dari tempat-tempat pengumpulan". ${ }^{6}$ Tempat pembuangan sampah seharusnya dekat dengan sumber sampah agar proses pengelolaannya lebih cepat dan meminimalisisr biaya pengangkutan. Namun yang terjadi pada kotakota besar sampah dipusatkan pada satu lokasi pembuangan akhir sehingga biaya pengangkutan cukup tinggi dan mencemari udara saat sampah

Adrian R. Nugraha, Op. Cit.

Ibid,. Adrian R. Nugraha diangkut ke tempat pembuangan. Lokasi tempat pembuangan akhir yang jauh menyebabkan banyak orang yang membakar sampah yang dapat mencemari udara.

d) Penimbunan

Menurut Soma terdapat beberapa cara dalam penimbunan sampah diantaranya adalah open dumping, dumping at sea, dan sanitary landfil.'

\section{1) Open Dumping}

Open dumping atau penimbunan terbuka yaitu dengan cara membuang dan menumpuk sampah ditempat terbuka. Penimbunan terbuka merupakan cara yang sederhana dalam penangan sampah, namun terdapat keuntungan dan kerugiannya.

\section{2) Dumping at Sea}

Dumping at sea adalah penimbunan yang di lakukan di pantai. Penimbunan di pantai ini dilakukan dengan cara membuat tanggultanggul pemisah untuk menghalangi sampah agar tidak terbawa ombak. Setelah dibuat tanggul maka sampah ditimbun dan jika sudah penuh maka diratakan dengan pasir. Lama kelamaan tempat ini akan menjadi subur dan dapat ditanami pepohonan dan bisa dijadikan pemukiman. Cara penimbunan ini memiliki keuntungan dan kerugian.

\section{3) Sanitary Landfill}

Sanitary Landfill adalah menimbun sampah di dalam tanah. Menurut Soekmana Soma, "secara definisi sanitary landfill adalah suatu kegiatan membuang sampah setiap hari ke suatu tempat kemudian dilakukan penutupan pada akhir pembuangan." Menimbun sampah di dalam tanah yaitu dengan cara menggali tanah dengan kedalaman tertentu lalu sampah dimasukkan kedalam lubang dan setelah sampah penuh lalu dipadatkan dan di timbun lagi dengan tanah lalu dipadatkan. Penimbunan jenis ini tentunya memiliki keuntungan diantaranya menimbun berbagai jenis sampah dengan jumlah yang besar, modalnya relatif kecil, dan lahan akan menjadi lebih subur dan kerugiannya dapat mencemari air tanah.

7 Soekmana Soma, Pengantar Ilmu Teknik, Lingkungan Seri: Pengelolaan Sampah Lingkungan (Bogor: IPB Press, 2010), h. 18. 


\section{Metode Penelitian}

Metode dalam penulisan ilmiah ini adalah metode deskriptif. Data di peroleh melalui observasi dan analisis dari data sekunder. Data sekunder dalam penelitian ini antara lain data jumlah penduduk, peta administratif, data daerah pelayanan. Data yang telah terkumpul, baik data primer maupun data sekunder, dianalisis untuk kemudian diketahui hasilnya. Adapun hasil yang ingin diketahui adalah sebagai berikut: proyeksi jumlah Penduduk rentang tahun 2010-2025, volume sampah, jumlah TPS dan estimasi jumlah armada pengangkut (truk) untuk pengangkutan sampah.

(1) Perhitungan Proyeksi Jumlah Penduduk

Rumus Proyeksi Jumlah Penduduk

$$
\begin{aligned}
& \operatorname{Pn}=\operatorname{Po}(1+\text { n.r }) \\
& \text { (Sumber: Alfredo, 1987) }
\end{aligned}
$$

Dimana

Pn : Jumlah penduduk pada tahun ke-n

Po : Jumlah penduduk mula-mula.

$\mathrm{n}$ : Periode waktu proyeksi

$\mathrm{r}: \%$ pertumbuhan penduduk tiap tahun

(2) Perhitungan Volume Sampah yang dihasilkan Penduduk dalam satu hari.

Adapun untuk menghitung jumlah volume sampah yang dihasilkan penduduk perhari dilakukan dengan menerapkan rumus yang dikembangkan oleh Enri Damri, bila pengamatan lapangan belum tersedia, maka untuk menghitung besaran sistem, dapat digunakan angka timbulan sampah sebagai berikut':

Satuan timbulan sampah kota besar $=2$ $-2,5 \mathrm{~L} /$ orang/hari, atau $=0,4-0,5 \mathrm{~kg} /$ orang/hari

* Satuan timbulan sampah kota sedang/kecil $=1,5-2 \mathrm{~L} /$ orang $/$ hari, atau $=0,3-0,4$ $\mathrm{kg} /$ orang/hari

Karena timbulan sampah dari sebuah kota sebagian besar berasal dari rumah tangga, maka untuk perhitungan secara cepat satuan timbunan sampah tersebut dapat dianggap sudah meliputi sampah yang ditimbulkan oleh setiap orang dalam berbagai kegiatan dan berbagai lokasi, baik saat di rumah, jalan, pasar, hotel, taman, kantor dsb.

\section{(3) Perhitungan Kebutuhan TPS (Tempat Pembuangan Sementara)}

Untuk menghitung jumlah TPS, digunakan rumus perhitungan menurut Hendrawan (2004), yaitu sebagai berikut: ${ }^{10}$

Dimana

$$
\text { Ntpsn }=\frac{\text { VSn VSn }}{\text { VTPSVTPS }}
$$

Ntpsn :Jumlah TPS yang dibutuhkan pada tahun ke $\mathrm{n}$

VSn : Volume sampah pada tahun ke $\mathrm{n}$

VTPS : Kapasitas TPS

\section{(4) Analisis Faktor Pengangkutan Sampah \\ Manajemen}

Menurut Tchobanoglous (1993) ada manajemen pengangkutan sampah terdapat beberapa hal yang harus diperhatikan dalam menganalisis tingkat pelayanan yang diberikan pada masyarakat, yaitu:

(a) Waktu Pengangkutan Tiap Rit ( Ta)

$$
\begin{aligned}
& \mathrm{tA}=\frac{\operatorname{Jarak}(S \mathrm{G}) \operatorname{Jarak}(S \mathrm{G})}{V t+V 0) / 2}+\mathrm{t}_{\text {in }} \\
& +\mathrm{t}_{\text {out }}
\end{aligned}
$$

Dimana

tA : Waktu angkut (Jam)

tin : Waktu menaikkan dan mengosongkan kontainer (Jam)

tout : Waktu menurunkan kontainer (Jam)

$S$ : Jarak dari pool-TPS-TPA $(\mathrm{Km})$

$\mathrm{V} 1$ : Kecepatan isi ( $\mathrm{Km} / \mathrm{Jam})$

V0 : Kecepatan kosong (Km/Jam)

\section{(b)Jumlah Rit (P)}

Dimana

$$
\mathrm{P}=\frac{V S V S}{V B V B}
$$

$P \quad:$ Jumlah pengambilan (rit)

$V S$ : Volume sampah (m3)

VB: Kapasitas truk (m3/rit)

10 Hendrawan, Analisa sampah perkotaan studi kasus Kota Denpasar. Tugas Akhir, (Denpasar; Universitas Udayana, 2004). 
(c) Waktu Operasi

(to) jika menggunakan satu truk:

$$
\mathrm{t}_{\mathrm{o}}=\mathrm{P} \times \mathrm{tA}
$$

\section{Dengan}

to : Waktu operasi pengangkutan sampah dari TPS ke TPA per hari (jam)

$P$ : Jumlah pengambilan (rit)

tA : Waktu angkut (jam)

\section{(d) Jumlah truk yang diperlukan (nt)}

$$
\mathrm{n}_{\mathrm{t}}=\frac{\text { toto }}{\text { tbtb }}
$$

\section{Dengan}

nt : Jumlah truk yang diperlukan (unit)

to : Waktu operasi pengangkutan sampah dari TPS ke TPA per hari (jam)

tb : Jumlah jam kerja per hari (jam)

\section{Hasil dan Pembahasan}

\section{Gambaran Umum Wilayah Penelitian}

Kecamatan Pondok Gede merupakan kawasan perbatasan antara DKI Jakarta dan Provinsi Jawa Barat. Pondok Gede adalah salah satu gabungan dari wilayah Pondok Melati, Jatiwaringin, Jatiwarna, Jatiasih, Jatimakmur, Jatibening, jatikarya dan sebagian wilayah Jakasampurna. Secara Geografis Kecamatan ini terletak :

Sebelah Utara berbatasan dengan Kecamatan Makasar dan Cipayung, Sebelah Selatan berbatasan dengan Kecamatan Arahan, Sebelah Timur berbatasan dengan Kecamatan Indramayu, Sebelah Barat berbatasan dengan Kecamatan Makasar dan Cipayung

\section{Peta Administrasi Kota Bekasi}

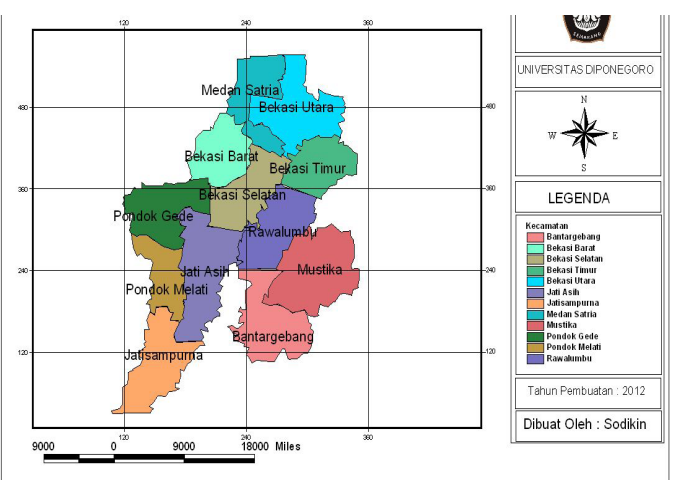

Kondisi topografi kota Bekasi dengan kemiringan antara $0-2 \%$, dan Pondok Gede ini termasuk ke dalam daerah yang memiliki ketinggian $<25 \mathrm{mdpl}$. Wilayah dengan ketinggian dan kemiringan rendah yang menyebabkan daerah tersebut banyak genangan, terutama pada saat musim hujan.

2. Estimasi Volume Sampah dan Jumlah TPS Tahun 2010-2025

Volume sampah dalam sebuah kawasan sangat ditentukan oleh besarnya jumlah penduduk, semakin besar jumlah penduduk volume sampah cenderung meningkat, hal ini sejalan dengan aktivitas manusia dalam kehidupan yang tidak terlepas dari sampah. Estimasi jumlah penduduk, volume sampah, dan jumlah TPS yang dibutuhkan sangat penting guna menunjang perencanaan dan strategi pengelolaan dan manajemen pengangkutan sampah. Oleh karena itu untuk menentukan volume sampah yang dihasilkan dan jumlah TPS yang dibutuhkan di Kecamatan Pondok Gede perharinya, langkah pertama adalah menentukan proyeksi penduduk dalam rentang waktu tahun 2010 sampai dengan tahun 2025 dan ditentukan estimasi volume sampah dihasilkan serta menentukan jumlah TPS yang dibutuhkan.

Berdasarkan hasil analisis dengan memperhitungkan besarnya jumlah penduduk pada tahun 2010 dan memproyeksikannya ke rentang tahun 2010-2025 di dapat hasil seperti terlihat pada Tabel 1 (hal. 55).

Berdasarkan hasil analisis menunjukan bahwa volume sampah pada awal tahun 2010 dengan jumlah penduduk 235.579 jiwa adalah $188.464 \mathrm{~m}^{3}$ / hari dan dari hasi proyeksi jumlah penduduk diprediksikan pada tahun tahun 2025 jumlah penduduk akan menjadi 358.551 jiwa dan volume sampah akan mengalami peningkatan dan dari tahun ke tahun akan mengalami kenaikan menjadi $322.696 \mathrm{~m}^{3}$ / hari. $\mathrm{Hal}$ ini terjadi karena pertumbuhan penduduk di Kecamatan Pondok Gede cukup besar ratarata laju pertumbuhan penduduk per tahun adalah sebesar 3,48 \%. Adapun jumlah TPS yang dibutukan berdasarkan tabel di atas baik yang berukuran $0,36 \mathrm{~m}^{3}$ maupun ukuran $4 \mathrm{~m}^{3}$, dari tahun ke tahun mengalami peningkatan 
Tabel 1. Estimasi Jumlah Penduduk dan Volume Sampah yang dihasilkan Rentang Tahun 20102025

\begin{tabular}{|c|c|c|c|c|c|c|c|}
\hline Tahun & $\begin{array}{l}\text { Proyeksi } \\
\text { Penduduk }\end{array}$ & $\begin{array}{c}\% \% \\
\text { Terlayani }\end{array}$ & $\begin{array}{l}\text { Penduduk } \\
\text { terlayani }\end{array}$ & $\begin{array}{l}\text { Timbunan } \\
/ \mathrm{H} / \mathrm{o} / \mathrm{M}^{3}\end{array}$ & $\begin{array}{l}\text { Volume } \\
/ \mathrm{H} / \mathbf{M}^{3}\end{array}$ & $\begin{array}{l}\text { TPS } \\
(0,36 \mathrm{M} 3) \\
\text { Unit }\end{array}$ & $\begin{array}{c}\text { TPS }\left(4 \mathbf{M}^{3}\right) \\
\text { Unit }\end{array}$ \\
\hline $\begin{array}{l}2010 \\
2011 \\
2012 \\
2013 \\
2014 \\
2015 \\
2016 \\
2017 \\
2018 \\
2019 \\
2020 \\
2021 \\
2022 \\
2023 \\
2024 \\
2025\end{array}$ & $\begin{array}{l}235.579 \\
243.777 \\
251.975 \\
260.173 \\
268.372 \\
276.569 \\
284.768 \\
292.966 \\
301.164 \\
309.362 \\
317.560 \\
325.759 \\
333.957 \\
342.155 \\
350.353 \\
358.551\end{array}$ & $\begin{array}{l}40 \\
40 \\
40 \\
40 \\
40 \\
40 \\
40 \\
45 \\
45 \\
45 \\
45 \\
45 \\
45 \\
45 \\
45 \\
45\end{array}$ & $\begin{array}{r}94.231 \\
97.510 \\
100.790 \\
104.069 \\
107.349 \\
110.628 \\
113.907 \\
131.835 \\
135.524 \\
139.213 \\
142.902 \\
146.591 \\
150.281 \\
153.969 \\
157.659 \\
161.348\end{array}$ & $\begin{array}{l}0.002 \\
0.002 \\
0.002 \\
0.002 \\
0.002 \\
0.002 \\
0.002 \\
0.002 \\
0.002 \\
0.002 \\
0.002 \\
0.002 \\
0.002 \\
0.002 \\
0.002 \\
0.002\end{array}$ & $\begin{array}{l}188.464 \\
195.022 \\
201.582 \\
208.138 \\
214.698 \\
221.256 \\
227.814 \\
263.670 \\
271.048 \\
278.426 \\
285.804 \\
293.182 \\
300.562 \\
307.942 \\
315.318 \\
322.696\end{array}$ & $\begin{array}{l}524 \\
545 \\
560 \\
579 \\
597 \\
615 \\
633 \\
733 \\
753 \\
774 \\
794 \\
815 \\
835 \\
856 \\
876 \\
897\end{array}$ & $\begin{array}{l}48 \\
49 \\
51 \\
53 \\
54 \\
56 \\
57 \\
66 \\
68 \\
70 \\
72 \\
74 \\
76 \\
77 \\
79 \\
81\end{array}$ \\
\hline
\end{tabular}

Tabel 2. Kebutuhan Sarana untuk Pengangkutan Sampah di Kecamatan Pondok Gede Tahun 2010-2025

\begin{tabular}{|c|c|c|c|c|}
\hline Tahun & $\begin{array}{l}\text { Volume Sampah } \\
\text { Terlayani } / \mathrm{m}^{3} / \mathrm{h}\end{array}$ & $\begin{array}{c}\text { Jumlah rit jika } \\
\text { menggunakan } 1 \text { truk } \\
\text { (unit) }\end{array}$ & $\begin{array}{c}\text { Waktu Operasi Jika } \\
\text { menggunakan } 1 \text { Truk } \\
\text { (jam) }\end{array}$ & $\begin{array}{c}\text { Jumlah } \\
\text { Truk yang } \\
\text { dibutuhkan } \\
\text { (unit) }\end{array}$ \\
\hline $\begin{array}{l}2010 \\
2011 \\
2012 \\
2013 \\
2014 \\
2015 \\
2016 \\
2017 \\
2018 \\
2019 \\
2020 \\
2021 \\
2022 \\
2023 \\
2024 \\
2025\end{array}$ & $\begin{array}{l}188.464 \\
195.022 \\
201.582 \\
208.138 \\
214.698 \\
221.256 \\
227.814 \\
263.67 \\
271.048 \\
278.426 \\
285.804 \\
293.182 \\
300.562 \\
307.942 \\
315.318 \\
322.696\end{array}$ & $\begin{array}{l}30 \\
31 \\
32 \\
34 \\
35 \\
36 \\
37 \\
42 \\
44 \\
45 \\
46 \\
48 \\
49 \\
51 \\
52\end{array}$ & $\begin{array}{l}60 \\
62 \\
64 \\
67 \\
69 \\
71 \\
73 \\
84 \\
87 \\
89 \\
91 \\
94 \\
96 \\
98 \\
101 \\
103\end{array}$ & $\begin{array}{l}7 \\
7 \\
8 \\
8 \\
8 \\
8 \\
9 \\
10 \\
10 \\
10 \\
11 \\
11 \\
11 \\
11 \\
12 \\
12\end{array}$ \\
\hline
\end{tabular}

Sumber : Hasil Ananlisis Tabun 2015

dimulai pada tahun 2010 kebutuhan TPS adalah 524 unit untuk yang berukuran $0,36 \mathrm{~m}^{3}$ dan ukuran $4 \mathrm{~m}^{3}$ dibutuhkan 48 unit. Pada tahun 2025 setelah dilakukan analisis pada tahun 2025 kebutuhan TPS meningkat menjadi 897 unit untuk yang berukuran $0,36 \mathrm{~m}^{3}$ dan 81 unit untuk yang berukuran $4 \mathrm{~m}^{3}$.

Dengan diketahuinya sampah yang dihasilkan masyarakat maka direncanakan jumlah TPS (Tempat Pembuangan Sementara) agar semua sampah dapat tertampung.

3. Menenjemen Pengangkutan Sampah Pada Tahun 2010-2025

Untuk menunjang Pengangkutan yang efektif dibutuhkan manajemen pengangkutan baik. Misalnya dengan menentukan jumlah rit dan berapa truk yang dibutukan agar semua sampah bisa terangkut. Sampah yang sudah terkumpul di TPS maupun pool di Kecamatan Pondok Gede ini akan dibuang ke TPA Bantar Gebang yang memiliki jarak sekitar $20 \mathrm{~km}$. truk yang digunakan adalah truk yang memiliki kapasitas $6 \mathrm{~m}^{3} /$ unit. Tabel di bawah ini akan menjelaskan tentang kebutuhan sarana truk dan waktu yang diperlukan untuk pengangkutan sampah di Kecamatan Pondok Gede Kota Bekasi.

Berdasarkan Tabel 2 diatas, jumlah pengangkutan (rit) yang ideal dengan asumsi menggunakan 1 armada truk, rentang tahun 2010 sampai dengan 2014 adalah 30 rit dan setiap tahunnya mengalami peningkatan sehingga pada tahun 2025 menjadi 52 rit. Adapun waktu operasi yang diperlukan apabila menggunakan 1 truk seiring dengan peningkatan jumlah penduduk dan peningkatan volume sampah yang dihasilkan waktu operasi ikut mengalami penambahan seperti yang terlihat pada Tabel 2 
di atas untuk tahun 2010 waktu yang diperlukan adalah 60 jam dan pada tahun 2025 adalah 103 jam. Kebutuhan truk yang ideal agar semua sampah yang dihasilkan penduduk dapat terangkut, dalam analisis ini jenis truk yang digunakan adalah truk dengan daya tampung $6 \mathrm{~m}^{3}$ Berdasarkan hasil analisis rentang tahun 2010-2011 adalah 7 unit, dan berangsur-angsur mengalami peningkatan sehingga pada tahun 2025 truk yang dibutuhkan menjadi 12 unit.

\section{E. Penutup}

Kecamatan Pondok Gede adalah kecamatan yang terletak di perbatasan antara Kota Bekasi dengan Jakarta Timur. Volume Sampah yang dihasilkan penduduk kecamatan Pondok Gede setiap harinya pada tahun awal atau tahun 2010 dengan jumlah penduduk 235.579 jiwa adalah $188.464 \mathrm{~m}^{3}$, namun setelah memproyeksikan penduduk pada tahun 2025 total penduduk diprediksikan akan menjadi 358.551 jiwa dan volume sampah menjadi $322.696 \mathrm{~m}^{3} /$ hari. Hal ini menunjukan bahwa di Kecamatan Pondok Gede dibutuhkan manajemen pengangkutan yang tepat. Berdasarkan hasil analisis diketahui kebutuhan untuk TPS dengan ukuran $0,36 \mathrm{~m}^{3}$ dari tahun ke tahun mengalami peningkatan sehingga pada tahun 2025 adalah 897 unit. Begitu pula untuk jumlah truk yang dibutuhkan juga mengalami peningkatan dimulai dari tahun 2010 jumlah truk yang dibutuhkan adalah 7 unit sampai pada tahun 2025 jumlah truk yang dibutukan menjadi 12 unit. Hal ini dilakukan agar semua sampah dari penduduk yang terlayani dapat terangkut dan menciptakan lingkungan yang bersih di kecamatan Pondok Gede.

\section{F. Daftar Pustaka}

Alfredo, A. (1987). Probability Concepts In Engineering Planning And Design. First edition. USA: John Wiley \& Sons, Inc.

Arikunto, S. (1990). Prosedur Penelition (Suatu Praktek). Jakarta: Bina Aksara.

Bahar, Yul Harry. (1986). Teknologi Penangan dan Pemanfaatan Sampah. Jakarta: PT. Wacana Utama Pramesti.
Bintarto, R dan Hadisumarno, S. (1987). Metode Analisa Geografi. Jakarta: LP3ES.

Damanhuri, E. 1995. Teknik Pembuangan Akbir, Jurusan Teknik Lingkungan, Fakultas Teknik Sipil dan Perencanaan, Institut Teknologi Bandung.

Faizah. 2008. Pengelolaan Sampah Rumah Tangga Berbasis Masyarakat (Studi Kasus di Kota Yogyakarta). Tesis Magister Ilmu Lingkungan. Universitas Diponegoro. Semarang.

Hendrawan. (2004). Analisa Sampah Perkotaan Studi Kasus Kota Denpasar. Tugas Akhir. Denpasar. Universitas Udayana.

Nugraha, Adrian R. (2010). Menyelamatkan Lingkungan Hidup dengan Pengelolaan Sampah. Jakarta: PT. Cahaya Pustaka Raga.

Samekto, C dan Ewin, S. W. (2010). Potensi Sumber Daya Air di Indonesia. Jakarta: Direktorat Rawa dan pantai Kementerian PU.

Soewarno, E. (1987). Metode Kuantitatif Dalam Penelitian Ilmu-Ilmu Sosial dan Pendidikan. Jakarta: Depdikbud.

Soma, Soekmana. (2010). Pengantar Ilmu Teknik Lingkungan Seri : Pengelolaan Sampah Lingkungan. Bogor: IPB Press.

Sumaatmadja, N. (1988). Studi Geografi Suatu Pendekatan dan Analisa Keruangan. Bandung: Alumni.

Surbakti, Sriliani. (2009). Potensi Pengelolaan Sampah Menuju Zero Waste yang Berbasis Masyarakat di Kecamatan Kedungkandang Kota Malang. Laporan Penelitian Institut Teknologi Surabaya.

Surochiem. (2001). "Dimensi-dimensi penting Monitoring Pelaksanaan Program Pemberdayaan dan Partisipasi pada Masyarakat Pesisir" dalam Jurnal Neptunus 8(1) Maret 2001 50-56, Surabaya.

Syafrudin. (2004). Model Pengelolaan Sampah Berbasis Masyarakat (Kajian Awal Untuk Kasus Kota Semarang), Makalah pada Diskusi Interaktif: Pengelolaan Sampah Perkotaan secara Terpadu, Program Magister Ilmu Lingkungan UNDIP. 
Tchobanoglous, George, Theisen, Hilary, Vigil. (1993). Integrated Solid Waste Management. Singapura : Mc Graw Hill.
Umar, Ibnu. (2009). Pengelolaan Sampah Secara Terpadu di Wilayah Perkotaan. Jakarta: Jurnal Lingkungan Hidup. 